\title{
Low-fat diets and energy balance: how does the evidence stand in 2002?
}

\author{
Arne Astrup*, Benjamin Buemann, Anne Flint and Anne Raben \\ The Research Department of Human Nutrition and The Centre for Advanced Food Studies, The Royal Veterinary and \\ Agricultural University, Rolighedsvej 30, DK-1958 Frederiksberg C, Denmark
}

\begin{abstract}
The role of high-fat diets in weight gain and obesity is assessed by evidence-based principles. Four meta-analyses of weight change occurring on ad libitum low-fat diets in intervention trials consistently demonstrate a highly significant weight loss of $3-4 \mathrm{~kg}$ in normal-weight and overweight subjects $(P<0.001)$. The analyses also find a dose-response relationship, i.e. the reduction in percentage energy as fat is positively associated with weight loss. Weight loss is also positively related to initial weight; a $10 \%$ reduction in dietary fat is predicted to produce a $4-5 \mathrm{~kg}$ weight loss in an individual with a BMI of $30 \mathrm{~kg} / \mathrm{m}^{2}$. The non-fat macronutrient composition of the diet is also important. Whereas the glycaemic index of the carbohydrate may play a role for cardiovascular risk factors, there is so far no evidence that low-glycaemic index foods facilitate weight control. In contrast, intervention studies show that sugar in drinks is more likely to produce weight gain than solid sugar in foods. Although the evidence is weak, alcoholic beverages promote a positive energy balance, and wine may be more obesity-promoting than beer. Protein is more satiating and thermogenic than carbohydrates, and one intervention study has shown that an $a d$ libitum low-fat diet where carbohydrate was replaced by protein produced more weight loss after 6 months $(8.1$ v. $5.9 \mathrm{~kg})$. The evidence linking particular fatty acids to body fatness is weak. If anything, monounsaturated fat may be more fattening than polyunsaturated and saturated fats, and no ad libitum dietary intervention study has shown that a normal-fat high-monounsaturated fatty acid diet is equivalent or superior to a low-fat diet in the prevention of weight gain and obesity. The evidence strongly supports the low-fat diet as the optimal choice for the prevention of weight gain and obesity, while the use of a normal-fat high-monounsaturated fatty acid diet is unsubstantiated.
\end{abstract}

Low-fat diets: Weight loss: Obesity: Body-weight regulation

\section{Evidence-based dietary guidelines}

In order to prevent cardiovascular disease, cancer, obesity and type 2 diabetes it is recommended that dietary fat should be reduced from the 35-45\% total energy content currently normal in most Western diets to $<30 \%$ (National Institutes of Health, 2000), or to 25-35\% (Expert Panel on Detection, Evaluation, and Treatment of High Blood Cholesterol in Adults, 2001). However, new research has demonstrated that it is not total fat, but rather high intakes of saturated fat and trans-fatty acids that are atherogenic and contribute to cardiovascular disease, whereas monounsaturated fatty acids (MUFA) and polyunsaturated fatty acids (PUFA) are considered to be more neutral. This finding has been translated into the public health recommendations by a number of scientists as meaning that it is not the total fat content of the diet that counts, but that it is rather the type of fat eaten that is important. They conclude that recommending a reduction in total dietary fat is misleading and unnecessary. Furthermore, it has been claimed that low-fat diets may adversely affect cardiovascular risk factors, and the epidemiologist Walter Willett promotes an alternative diet with a higher content of total fat based on MUFA and PUFA (Katan et al. 1997). Willett (1998) also claims that there is little if any evidence that dietary fat plays a role in energy balance and obesity. A comprehensive article entitled 'The soft science of fat' with the heading 'Mainstream nutritional science has demonised dietary fat, yet 50 years and hundreds of millions of dollars of research have failed to prove that eating a low-fat diet will help you live longer' by the journalist Gary Taubes (2001), has recently been published as an editorial in the prestigious journal Science. We have found this view biased 
Table 1. Strength of recommendations according to categories of evidence (evidence-based guidelines)

A Evidence from meta-analysis of randomised trials and from at least one randomised controlled trial

B Evidence from at least one controlled study without randomisation and at least one other type of quasi-experimental study

C Evidence from observational studies such as comparative, correlation and case-control studies

D Evidence from expert committee reports, or opinions or clinical experience of respected authorities, or both

and unsubstantiated (Marckmann \& Astrup, 2000; Astrup et al. 2001).

The various new recommendations seem to be readily accepted by the public, and the present review focuses on the evidence in favour of a low-fat diet $(<30 \%$ energy from fat) $v$. a normal-fat $(30-40 \%)$ high-MUFA diet for the prevention of obesity, type 2 diabetes and cardiovascular disease.

We aim to use the evidence-based principle to assess the sufficiency of the existing documentation to substantiate whether one of the diets is superior to the other (Eccles et al. 1998). Notably, meta-analysis of randomised controlled trials is recognised as being the strongest evidence, followed by experimental studies. Observational epidemiological studies are ranked at the bottom of the scale, with only opinions or clinical experience of respected authorities ranking lower (Table 1).

\section{The evidence linking dietary fat to energy balance and obesity}

It is obvious that the possible link between dietary fat content and obesity must be exerted through an effect of dietary fat on energy balance. A positive energy balance can be facilitated, in theory, by a high-fat diet through the promotion of overconsumption of energy, e.g. due to a lower satiating effect per J of a high-fat $v$. a low-fat diet. Moreover, energy from fat could be more effectively absorbed from the intestine than carbohydrate and protein, and fat may also reduce energy expenditure, e.g. by a lower thermogenic effect of fat compared with carbohydrate and protein. It is likely that the effect on energy balance is predominantly exerted through an effect on intake, and the relationship between dietary fat and body fat should therefore be studied under ad libitum conditions, where the studied individuals have free access to food. Consequently, studies where different diets are compared in isoenergetic amounts can only provide information about an effect on absorption and energy expenditure.

We are aware of four meta-analyses of controlled trials comparing low-fat diets with normal-fat diets as a control under ad libitum conditions. In a systematic review and meta-analysis based on twenty-eight intervention trials Bray \& Popkin (1998) found that a reduction of $10 \%$ in the amount of energy from fat was associated with a reduction in weight of $16 \mathrm{~g} / \mathrm{d}$. This rate of reduction corresponds to a weight loss of $2.9 \mathrm{~kg}$ over 6 months. We have conducted a more restrictive meta-analysis, including only studies with no intervention other than the ad libitum low-fat diet and a proper control (Astrup et al. 2000b). This analysis included a total of 1728 individuals, 1074 women and 654 men. Thirteen studies were randomised controlled trials, of which twelve used a parallel design and one used a cross-over design. The control groups were either advised to continue their regular diet, or advised to consume a diet with a fat content comparable with that of the background population. The low-fat interventions produced a weight loss of $2.4 \mathrm{~kg}$ more than that of the control groups (95\% CI 1.9, 2.9; $P<0.0001)$ in the fixed-effects analysis, and $2.5 \mathrm{~kg}$ more than in the control groups $(95 \%$ CI $1.5,3 \cdot 5 ; P<0.0001)$ in the random-effects analysis. In a simple correlation analysis the major determinant of the weight-loss difference was pretreatment body weight $(r 0.52, P<0.05)$. There was a dose-response relationship between the reduction in percentage dietary fat intake and weight loss after adjustment for pretreatment body weight, $(r 0 \cdot 66, P<0 \cdot 005)$. With no change in percentage dietary fat intake, no weight change occurred (intercept with $0, P=0 \cdot 14$ ). The slope of the relationship indicated that for every $1 \%$ reduction in dietary fat a weight loss of $0.37 \mathrm{~kg}(0.15-0.60 \mathrm{~kg} / \%)$ was achieved. Weight loss was not associated with the duration of the intervention (Astrup et al. 2000b).

Another meta-analysis, based on thirty-seven dietary intervention studies, found weight loss for the intervention groups to be $2.79 \mathrm{~kg}$ larger than that for the control groups, and there was a relationship between reduction in dietary fat and weight loss (Yu-Poth et al. 1999). For every $1 \%$ decrease in energy from fat there was a $0.28 \mathrm{~kg}$ decrease in body weight. Subsequently, we updated our initial meta-analysis and excluded trials in which the intervention group was instructed to increase physical activity in any way. Two authors, independently of each other, selected the studies meeting the inclusion criteria and extracted data from sixteen trials (duration of $>2$ months) with nineteen intervention groups, and enrolling a total of 1910 individuals. Fourteen of these studies were randomised. Weight loss was not the primary aim in eleven studies. Before the interventions the mean percentage of dietary energy from fat in the studies was 37.7 for the low-fat groups, and 37.4 for the control groups. The low-fat intervention produced a mean fat reduction of $10.2(95 \% \mathrm{CI}$ 8.1-12.3) \%. Low-fat intervention groups showed a greater weight loss than control groups $(3.2(95 \%$ CI $1.9,4.5) \mathrm{kg}$; $P<0.0001)$, and a greater reduction in energy intake $(1138$ (95\% CI 564, 1712) kJ/d; $P<0.002)$. A pretreatment body weight $10 \mathrm{~kg}$ higher than the average was associated with a $2.6 \mathrm{~kg}$ greater difference in weight loss (Astrup et al. $2000 a$ ). These four meta-analyses thus consistently show that a reduction in dietary fat without restriction of total energy intake causes a reduction in energy intake and weight loss in a dose-dependent fashion, and may produce a modest, but clinically relevant, weight loss in overweight subjects.

In a rebuttal of the previously mentioned Science paper 'The soft science of dietary fat' (Taubes, 2001) we pointed out that the author did not mention the evidence provided by these meta-analyses, which clearly show reduced energy intakes and weight loss on the low-fat diets (Astrup et al. 2001). He replied, 'they say that meta-analyses demonstrate that low-fat diets are efficient weight loss diets, yet there are 
trials and even meta-analyses - a controversial tool, in any event - that suggest the opposite' (Taubes, 2001). We have been unable to identify these trials and meta-analyses from the literature, congress proceedings and networks and question their existence. We are also concerned about the signal that Science does not recognise the evidence-based principle (Eccles et al. 1998).

The typical weight loss of $3-4 \mathrm{~kg}$ produced by ad libitum low-fat diets is more likely an underestimation of the true effect. Obviously, adherence to the low-fat diets can be difficult in a 'toxic high-fat environment', and if one could adjust the weight-loss results from poorly-compliant individuals the weight loss would probably be even better. A number of the trials have provided some evidence to support that possibility. Swinburn et al. (2001) found that weight loss on an ad libitum low-fat diet was $3.3 \mathrm{~kg}$ after 1 year. However, if the subjects in the intervention group were stratified according to compliance, assessed by attendance at the monthly meetings and completion of the diet diaries, one gets a better idea about the efficacy of the low-fat diet to produce weight loss (Fig. 1). While those subjects in the less-compliant group lost only about $1 \mathrm{~kg}$, the morecompliant group lost about $6 \mathrm{~kg}$ after 1 year (Swinburn et al. 2001). Moreover, it is evident that many individuals think that they are consuming a low-fat diet, but are not aware that many of the foods they eat have a high-fat content. Such factors will contribute to underestimating the real efficacy of low-fat diets.

Evidence from other lines of studies with lower evidence strength, such as experimental studies from Prentice, Stubbs, Blundell, our own group and others consistently

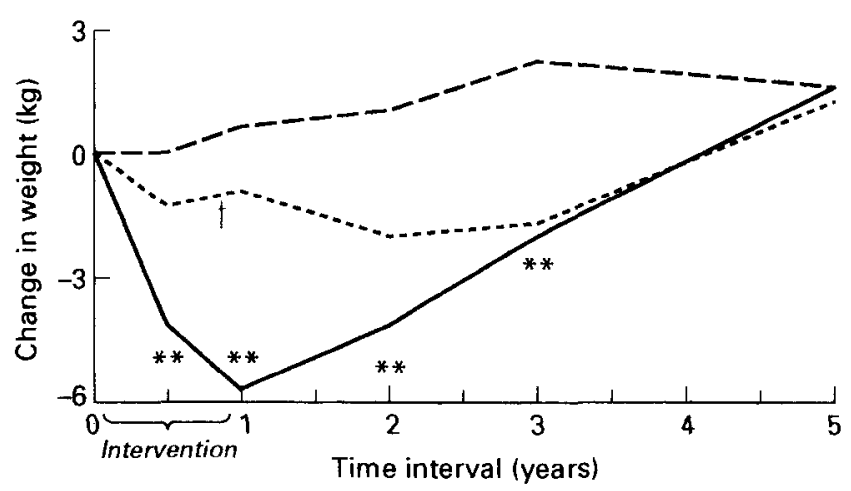

Fig. 1. Changes in body weight in a control group consuming a normal-fat diet ad libitum (-...-), and in the least (........)- and most (-)-compliant individuals in the ad libitum low-fat intervention group. Mean values for the most-compliant low-fat group were significantly different from that for the control group: ${ }^{\star \star} P<0.01$. Mean value for the least-compliant low-fat group was significantly different from that for the control group: $\dagger P<0.05$. The results indicate that the true efficacy of the low-fat diet is not the $3.3 \mathrm{~kg}$ weight loss observed after 1 year in the whole intervention group, but rather the $6 \mathrm{~kg}$ weight loss seen in the most-compliant group. It is also obvious from the weight course that the effect of the diet change is maintained only as long as the intervention is exerted. As soon as the intervention was stopped weight regain occurred, and after 5 years no effect was left as compared with the control group. As overweight is a chronic condition and a permanent lifestyle change is needed, future interventions should include reinforcement sessions to prevent relapse. (Reproduced with permission from Swinburn et al. 2001.) demonstrate that high-fat diets promote passive overconsumption of energy and increase the risk of weight gain and obesity (Astrup, 2001a). Observational studies, whether cross-sectional or longitudinal, also suggest that high dietary fat is positively associated with body weight and body fatness (Astrup, 2001b).

\section{The role of different carbohydrates}

The role of different types of carbohydrate in the regulation of body weight has not been investigated as thoroughly as the role of the total dietary fat content. A few recent studies have illuminated this area with regard to carbohydrate structure (e.g. simple or complex carbohydrates, sucrose or starch). The largest and most recent is the CARMEN multicentre trial, which involved a total of 316 overweight subjects in five different countries (Saris et al. 2000). In this study the impact of 6 months of ad libitum intake of low-fat diets, rich in either simple or complex carbohydrates, on energy intake, body weight and health variables was investigated. The results showed that both low-fat diets reduced body weight, by 1.6 and $2.4 \mathrm{~kg}$ respectively, compared with the normal-fat control diet. The slightly lower weight loss on simple carbohydrates than on complex carbohydrates did not reach statistical significance. The weight loss on both diets consisted entirely of fat mass. Furthermore, no detrimental effects on blood lipids were observed during consumption of either of the carbohydrate diets. According to this study the type of carbohydrate (simple sugars $v$. complex carbohydrates) does not seem to have much importance for body-weight regulation and risk factors, as was previously suggested.

The most probable reason for the observed weight losses on carbohydrate-rich diets is a spontaneous decrease in energy intake. Several mechanisms, probably all important, may be involved.

First, the low energy density of carbohydrates is important; $1 \mathrm{~g}$ carbohydrate $(17 \mathrm{~kJ} / \mathrm{g})$ provides less than half the energy of $1 \mathrm{~g}$ fat $(37 \mathrm{~kJ} / \mathrm{g})$. This factor means that a smaller amount of energy is consumed in a carbohydraterich meal than in a fat-rich meal of similar weight. Second, but relatedly, a starch- and fibre-rich diet often comprises a surprisingly large volume of foods. In one long-term study using such a diet the volunteers actually had problems consuming the large volume of food, especially the diets designed for the volunteers with the highest energy requirements. Several of the subjects initially complained of bowel distension and fullness (Raben et al. 1995). However, these side effects disappeared after some weeks. It is clear that a much greater volume must be consumed in order to obtain a certain energy intake on a carbohydrate-rich diet (Tremblay et al. 1991). It is therefore plausible that energy intake decreases acutely and body weight decreases in the long term. This factor is a great advantage with regard to overweight. In developing countries the same effects may be hazardous, and they are also a disadvantage for individuals participating in elite sports, where a carbohydrate-rich diet is needed to optimise performance (Costill, 1988). A third reason for a decreased energy intake is a slower gastric emptying rate on a fibre-rich diet. This effect, which may be related to an antral distension, is known to prolong feelings 
of fullness and satiety (Sepple \& Read, 1989; Jones et al. 1997).

Fourth, increased satiety due to increased plasma glucose (glucostatic theory) and liver glycogen concentrations (glycogenostatic theory) compared with a fat-rich diet may be important (Mayer, 1953; Russek, 1970; Shimizu et al. 1983). The glucostatic theory has been supported by studies finding positive correlations between postprandial satiety and changes in plasma glucose (Raben et al. 1996), and studies with rats and human subjects showing that meal initiation is preceded by a decrease in blood glucose concentration (Campfield et al. 1993; Campfield, 1997). However, not all studies support the glucostatic theory (Holt et al. 1992; Granfeldt et al. 1994). Newer studies suggest that the glucose-induced plasma insulin increase is an important central satiety signal (Schwartz, 2000; Verdich et al. 2001).

A fifth reason, which should also be considered, is the decreased energy availability of a high-fibre diet. The ingestion of 64 compared with $34 \mathrm{~g}$ dietary fibre/d for 10 weeks in lean healthy males resulted in a $5.7 \%$ lower protein utilisation and in a $3.0 \%$ lower fat utilisation (Miles, 1992). Total energy utilisation was $2.9 \%$ lower, equal to $400 \mathrm{~kJ} / \mathrm{d}$ (Miles, 1992). A theoretical calculation showed that if the fibre intake in a typical American diet was increased from $18 \mathrm{~g} / \mathrm{d}$ to $36 \mathrm{~g} / \mathrm{d}$ the amount of metabolisable energy would be reduced by $540 \mathrm{~kJ} / \mathrm{d}$ (Baer et al. 1997).

Finally, carbohydrate-induced increases in satiating hormones (insulin, noradrenaline, gastric inhibitory polypeptide, glucagon-like peptide) may also play an important role (Flatt et al. 1984; Smith \& Gibbs, 1987; Leibowitz, 1988; Schick et al. 1992; Raben et al. 1996; Flint et al. 2000).

\section{Can carbohydrates make you fat?}

Yes, if you are overfed energy in the form of carbohydrate. A recent study demonstrated that after massive carbohydrate overfeeding for $4 \mathrm{~d}(2.5 \times$ energy expenditure with ( $\%$ energy) 88 from carbohydrate, 10 from protein and 1-2 from fat) in healthy male subjects, net fat synthesis amounted to $170 \mathrm{~g} / \mathrm{d}$, but only $2 \%$ of this fat $(3 \mathrm{~g} / \mathrm{d})$ was produced in the liver, although hepatic de novo lipogenesis actually increased forty-fivefold (Aarsland et al. 1997). Thus, $98 \%$ of the net fat synthesis must have taken place in the adipose tissue (Aarsland et al. 1997). Normally, however, appetite regulatory mechanisms will prevent carbohydrate overfeeding, and thereby prevent de novo lipogenesis and fat deposition from taking place.

\section{Glycaemic index}

The long-term effects of a diet containing low- or highglycaemic index (GI) foods on body weight have been very poorly investigated. In one earlier study using different low-energy diets it was found that 12 weeks on a low-GI diet produced a significantly greater weight loss $(9.4 \mathrm{~kg})$ than a conventionally-balanced diet $(7.4 \mathrm{~kg})$ in obese hyperinsulinaemic females $(P<0.01$; Slabber et al. 1994). Conversely, no difference in body weight was observed in six patients with non-insulin-dependent diabetes mellitus after 6 weeks on isoenergetic diets with either high $(-2.5 \mathrm{~kg})$ or low $(-1.8 \mathrm{~kg} \mathrm{GI})$ (Wolever et al. 1992). In a more recent study, where weight maintenance was also intended, it was also not possible to maintain body weight in twenty patients with type 2 diabetes when they consumed either a low- or high-GI low-fat diet. Interestingly, body weight dropped similarly during both the low- and high-GI interventions ( 1.4 and $1.5 \mathrm{~kg}$ respectively; Järvi et al. 1999). However, in another study with isoenergetic intervention no changes or diet differences in body weight were produced by 3 weeks on high-or low-GI diets (Frost et al. 1998).

A study on overweight children (10 years of age, on average) has been published recently (Spieth et al. 2000). Two weight-loss regimens were tested, one was energy reduced and designed in accordance with the US dietary recommendations, i.e. (\% energy) 55-60 from carbohydrate, 15-20 from protein, 25-30 from fat. The other regimen was a non-energy-reduced diet designed to obtain the lowest possible GI, focusing on vegetables, pulses and fruit. This diet contributed (\% energy) 45-50 from carbohydrate, 20-25 from protein and 30-35 from fat. The results showed that a low-GI diet gave a weight loss $(-1.16 \mathrm{~kg})$ in contrast to the recommended diet $(+1.44 \mathrm{~kg} ; P<0.01)$. The results of the study are, however, very difficult to interpret in relation to the GI question, since a number of dietary factors apart from the GI were different in the two groups. For example, the intake of total energy, carbohydrate, protein and fat was also different. The same research group conducted another study on ten overweight younger men with BMI of about $30 \mathrm{~kg} / \mathrm{m}^{2}$ (Agus et al. 2000). This study comprised $7 \mathrm{~d}$ interventions with energy restriction to only $50 \%$ of the subjects' estimated daily energy needs. The high-GI diet contained (\% energy) 67 from carbohydrate, 15 from protein, and 18 from fat, while the low-GI diet contained (\% energy) 43 from carbohydrate, 27 from protein and 30 from fat. There were no differences in weight loss after the high-GI $(3.2 \mathrm{~kg})$ and low-GI $(3.6 \mathrm{~kg})$ interventions, but again many factors in the diets changed apart from the GI. In contrast to long-term studies a fairly large number of acute short-term studies have been conducted. In fifteen of thirty-five studies it was found that low-GI foods increased satiety, delayed return of hunger or decreased ad libitum food intake compared with high-GI foods. However, such short-term studies have the disadvantage of not predicting food intake during the next days or weeks if the diet is continued.

In a majority of the published studies a low-GI diet has been found to produce favourable effects on risk markers of diabetes and cardiovascular diseases compared with a high-GI diet. Since most of the intervention studies have used diets aiming at energy balance or energy reduction the effects on body weight are, however, still unclear.

\section{Sucrose $v$. artificial sweeteners}

\section{Intervention studies}

It can be speculated that the removal of sucrose (carbohydrate) from the diet will increase the relative dietary fat content, which would then result in increased energy intake and body weight in the long term (Lissner et al. 1987; Saris 
et al. 2000). However, a number of acute meal tests lasting from a few hours to $1-2 \mathrm{~d}$ have produced conflicting results (Blundell \& Hill, 1986; Rogers \& Blundell, 1989; Tordoff \& Alleva, 1990a; Canty \& Chan, 1991). In these studies sucrose typically has been exchanged for aspartame, saccharin and/or water, and postprandial appetite sensations and/or ad libitum food intake have been monitored. Shortterm studies, however, are not very informative, as appetite regulation and macronutrient balance probably do not adjust for the missing energy and sucrose (carbohydrate) until after some days on the diet (Astrup \& Raben, 1992).

Intervention studies lasting for weeks or months are therefore of more interest. The number of long-term intervention studies (without energy restriction) is small, and none has lasted more than 3 weeks (Porikos et al. 1982; Tordoff \& Alleva, 1990b). These intervention studies suggest that an increased intake of artificial sweeteners decreases energy intake and body weight compared with sucrose. We investigated the effect of 10 weeks of supplementation with either sucrose or artificial sweeteners on ad libitum food intake and body weight in two groups of overweight subjects. About $80 \%$ of the supplements were given as drinks and $28 \%$ of the energy intake came from sucrose in the sucrose group. Similar food items and volumes were given to the two groups. An increase in total energy intake $(2.6 \mathrm{MJ} / \mathrm{d})$, body weight $(1.6 \mathrm{~kg})$ and fat mass $(1.3 \mathrm{~kg})$ was seen in the sucrose group after 10 weeks, whereas a decrease in body weight and fat mass $(1.0 \mathrm{~kg}$ and $0.3 \mathrm{~kg}$ ) was seen in the artificial-sweetener group (Raben et al. 2002). One likely reason for the increased energy intake and body weight in the sucrose group is that about $70 \%$ of the sucrose came from fluids. Energy from fluids has been shown to be less satisfying than solid foods, and it is easier to overconsume energy from drinks than from solids (Di Meglio \& Mattes, 2000). That sucrose from fluids may be fattening was also suggested by a recent observational prospective study in children, reporting that those with a high intake of sugar-sweetened drinks were at an increased risk of becoming overweight (Ludwig et al. 2001). It may be advisable, therefore, for overweight subjects to choose drinks and foods containing artificial sweeteners rather than sucrose in order to prevent weight gain.

\section{Observational studies}

Epidemiological studies, on the other hand, have found a clear inverse relationship between sucrose intake and body weight, suggesting that sucrose may help prevent overweight (Reid \& Hammersley, 1998). Furthermore, a long-term epidemiological study reported a positive relationship between saccharin intake and weight change (Bolton-Smith \& Woodward, 1994). Another large population study disclosed that weight gain over 1 year was higher for users of artificial sweeteners than for non-users (Colditz et al. 1990). This finding suggests that artificial sweeteners do not prevent weight gain, but the apparent relationship is confounded by the fact that those choosing artificial sweeteners are more likely to be motivated by susceptibility to weight gain. Long-term slimming studies (with energy restriction) have shown that the inclusion of artificial sweeteners can increase compliance and quality of life, and help maintain an obtained weight loss (Stellman \& Garfinkel, 1986). For weight-concerned individuals not on a diet, however, the use of artificial sweeteners is normally motivated by a wish to reduce daily energy intake without changing the rest of the diet, as a strategy for maintaining or reducing body weight.

The observational studies addressing the associations between sucrose intake and body weight have not distinguished between solid and liquid sugar. Thus, the category A evidence (see Table 1) from intervention trials suggests that sugar-rich drinks may promote weight gain and obesity.

\section{Protein}

There is some concern that a high protein intake in infant formulas and during growth may increase the susceptibility to weight gain and obesity. However, a new study suggests that a high protein intake may be associated with a higher BMI due to a positive relationship with the size of the fat-free mass, not with the amount of body fat (Hoppe et al. 2001). There is also a large body of experimental data to suggest that in adults protein has a higher satiating power per unit energy than carbohydrate and fat. The impact on obesity and risk factors of replacing carbohydrate with protein in ad libitum low-fat diets has been addressed in only one clinical trial. Two fat-reduced diets $(30 \%$ total energy), a high-carbohydrate diet (protein $12 \%$ total energy) and a high-protein diet (protein $25 \%$ total energy) were compared in sixty-five obese patients (Skov et al. $1999 \mathrm{~b}$ ). Weight loss after 6 months was $5.1 \mathrm{~kg}$ in the highcarbohydrate group and $8.9 \mathrm{~kg}$ in the high-protein group, and more subjects lost $>10 \mathrm{~kg}$ in the high-protein group $(35 \%)$ than in the high-carbohydrate group $(9 \%)$. The protein-rich diet had no adverse effect on blood lipids, homocysteine levels (Haulrik et al. 2002), renal function (Skov et al. 1999a) or bone mineral density. Replacement of some dietary carbohydrate by protein in ad libitum low-fat diets may improve weight loss. More freedom to choose between protein-rich and complex-carbohydrate-rich foods may encourage obese subjects to choose more lean meat and dairy products, and hence improve adherence to low-fat diets in weight-reduction programmes.

In conclusion, a dietary protein content of up to $25 \%$ energy may be beneficial for weight regulation in adults (evidence category B; see Table 1). Protein allowances of more than $20 \%$ energy in diets for weight reduction and for diabetics should await confirmation of the positive results by more randomised trials.

\section{Effects of different types of fat on energy balance}

Although the same quantities of different types of fat contain almost the same amounts of energy, differences may exist in their potential to influence energy balance. Thus, energy expenditure as well as satiety, both of which influence the energy balance of ad libitum low-fat diets and weight-maintenance diets, have been shown to be affected by the quality of fat. In human subjects, in a cross-sectional observational study strong positive associations between the intake of MUFA and different indices of adiposity were 
found, whereas high intakes of PUFA and saturated fat were only weakly related to adiposity (Doucet et al. 1998). Similarly, in a cohort of women all lipids other than vegetable fat were positively related to BMI. Furthermore, the strongest positive association between a nutrient and BMI was found to be the intake of trans-fatty acids (Colditz et al. 1990).

It is known from animal studies that rats fed a diet rich in safflower oil (PUFA) demonstrate less accumulation of body fat than rats fed a diet rich in beef tallow (SFA) (Shimomura et al. 1990; Dulloo et al. 1995). This observation is probably due to a higher diet-induced thermogenesis, an elevated fat oxidation and a higher sympathetic activity (Shimomura et al. 1990; Matsuo et al. 1995). MUFA also seem to increase body weight more than PUFA (Dulloo et al. 1995). Other studies also report differences in fat accumulation, body fat distribution and oxidation rates as a result of diets varying in fatty acid composition, chain length and saturation (Hill et al. 1993).

The dietary amounts of unsaturated:saturated fatty acids possibly also affects energy expenditure in human subjects, since high polyunsaturated:saturated fatty acids has been shown to result in higher resting metabolic rates, higher diet-induced thermogenesis and higher fat oxidation rates than a low polyunsaturated:saturated fatty acids ratio (Jones et al. 1985, 1992; Jones \& Schoeller, 1988; van Marken Lichtenbelt et al. 1997). Further, the chain length, especially medium-chain triacylglycerols compared with long-chain triacylglycerols, has been in focus due to its ability to become readily oxidised and induce satiety (Scalfi et al. 1991; Dulloo et al. 1996; Stubbs \& Habron, 1996; Van Wymelke et al. 1998). This observation has created a strong interest in developing modified fats that are less likely to produce a positive energy balance. However, so far the attempts at placing medium-chain tri-acylglycerols in different positions on the glycerol backbone have not shown an additional positive effect on energy balance compared with physical mixtures of medium- and long-chain triacylglycerols (Bendixen et al. 2002).

On the other side of the energy balance equation a study on the effect of high-fat meals, differing in fatty acid composition, on post-ingestive satiety in lean subjects found that MUFA induced a lower level of satiety and a larger subsequent energy intake than PUFA and saturated fatty acids (Lawton et al. 2000). Intestinal infusions of linoleic acid concordantly result in a lower subsequent food intake than those of oleic and stearic acids. However, the different effects on energy expenditure, appetite and ad libitum energy intake were not confirmed in a recent study performed with overweight subjects, suggesting that differences exist between subject groups (A Flint, BH Jørgensen, A Raben, S Toubro and A Astrup, unpublished results).

Together, these preliminary reports suggest that some differences between fatty acids are apparent, but until clinical trials based on longer-term interventions have been conducted, some caution should be taken in recommending specific fat types in preference to others, e.g. replacement of PUFA with MUFA in diets for individuals susceptible to weight gain and obesity, despite the apparently more neutral effects of MUFA reported in some studies in relation to insulin resistance, type 2 diabetes, cardiovascular disease and cancer (see p. 305).

\section{Beer, wine and spirits}

Alcohol may comprise a substantial part of the total energy intake, even with non-abusive consumption. Studies using indirect calorimetry have shown that the thermogenic effect of a moderate alcohol intake corresponds to between 17.6 (Murgatroyd et al. 1996) and 28 (Suter et al. 1992)\% of the energy it provides. The earlier contention, based on studies with excessive intake in alcoholics (Pirola \& Lieber, 1972), that alcohol is a non-nutritious substance which is totally dissipated as heat, may therefore be a misconception. Alcohol is now referred to as the fourth macronutrient by some nutritionists.

But how does this special macronutrient fit into a dietary regimen which aims at body-weight control? There are several issues to be considered. Alcohol consumption may cause a less-restrained food intake, resulting in a greater energy intake at meals. Such an effect may be reflected by both a faster eating rate and an extended meal time when wine or beer are given as an appetiser compared with non-alcoholic drinks (Westerterp-Plantenga \& Werwegen, 1999). In addition, alcohol may bypass the satiating impact of other macronutrients mediated by the different gastrointestinal hormones. The response of gastrointestinal hormones to alcohol is sparsely elucidated, but pure alcohol has been reported not to elicit any cholecystokinin or gastrin release in normal subjects (Chari et al. 1996). However, inhibition of gastric emptying is probably a major factor for the role of these hormones in the termination of a meal, and alcohol has been shown to retard gastric emptying, by undefined mechanisms, when administered before a test meal (Barboriak \& Meade, 1970). A blunted or lacking hormonal response to alcohol ingestion and absorption may mean that the energy in alcohol may not be compensated for in the same manner as for the other macronutrients.

Acute studies of ad libitum food intake, comparing alcoholic beverages with drinks containing isoenergetic amounts of other macronutrients, have shown a higher energy intake with alcohol (Westerterp-Plantenga \& Werwegen, 1999). Other experiments have failed to demonstrate such a difference (Foltin et al. 1993; Mattes, 1996; Poppitt et al. 1996). However, no or incomplete compensations for the energy. in all sorts of beverages were detected in all these studies, suggesting that appetite regulation responds insufficiently to energy in liquid form. This observation has been supported by a more direct experimental approach, where ad libitum food intake was assessed when the diet was supplemented with a fixed carbohydrate supplement provided either as jelly beans or as soda water (Di Meglio \& Mattes, 2000). Alcohol consumption may therefore promote a positive energy balance simply through the ingestion of liquid energy.

Another concern is the capacity of alcohol to perturb the metabolism of other substrates. Being a 'toxic' compound, alcohol is oxidised to acetate as quickly as possible in the liver. Acetate, in turn, replaces fat as a substrate for peripheral oxidative metabolism. Furthermore, the detoxification of alcohol interferes with several metabolic 
pathways, and so favours the accumulation of fat over its combustion. Such effects may be reflected by the marked decline in fat combustion with a virtually unaffected carbohydrate oxidation observed with alcohol administration during $24 \mathrm{~h}$ indirect calorimetry (Suter et al. 1992). Reduced fat utilisation at the same time as a maintained rate of withdrawal from the carbohydrate stores may be hypothesised to establish a positive energy balance when access to food is unrestricted. However, respiration chamber studies with ad libitum food intake, where alcohol intake is manipulated for periods of about 1 week, are probably required to document such disturbances in macronutrient balances in human subjects.

Experiments performed in an artificial setting in a laboratory, however, are too removed from the normal situation to tell the whole story about the delicate interplay between the biological, psychological and social factors that determine the amount of food we eat. The best approach would be to introduce the alcohol manipulation with as little interference in the subjects' daily life as possible. This approach was attempted in one study in which fourteen male subjects were instructed to drink $270 \mathrm{ml}$ red wine at dinner over a 6-week period, but otherwise to continue their normal daily life (Cordain et al. 1997). When compared with a control period, where the subjects refrained from drinking alcohol, no differences were found in body weight, body fat or energy intake assessed by a $3 \mathrm{~d}$ dietary record. Unfortunately, there are no other studies from other study groups and with other alcoholic beverages to support these results.

With the lack of evidence from category A (see Table 1), we may turn to the epidemiological evidence. Does it confirm the popular stereotype of the beer belly? Most observational studies have, in fact, detected a negative association between the amount of alcohol consumption and body fatness in women, whereas the findings are very inconsistent in men (Hellerstedt et al. 1990). However, these observations may be confounded by several demographic factors such as education, urbanisation, income etc., which may be accounted for to some extent statistically. Nevertheless, there may still be some residual variation associated with factors that are difficult to assess, such as social capability and self-esteem. Furthermore, the fact that the outcomes of the different surveys are sensitive to the study population (e.g. selective underreporting) indicates that cultural factors such as the attitude towards drinking may be strong determinants of these relationships. Epidemiology does not seem, therefore, to provide any assurance that alcoholic beverages can be enjoyed regularly without the risk that they may compromise weight control.

In conclusion, restrictions should be imposed on the intake of any energy-dense beverage, alcoholic as well as non-alcoholic, if the aim is a spontaneous weight loss when changing to a low-fat diet. It may also be worth considering that wine, with its high energy density, could be more weight gain inducing than low-energy beer if body weight control is an important issue. Unpublished results (A Astrup, B Buemann, A Flint and A Raben) from our laboratory suggest that total energy intake at an ordinary meal may be higher if red wine is served ad libitum rather than beer or fizzy drinks. In this study energy intake from the beverage was higher with wine, and it was not compensated for in the food intake.

\section{Low-fat diets and cardiovascular risk}

It is often argued that a reduction in fat intake and an increase in carbohydrate intake produces a rise in plasma triacylglycerols and a fall in plasma HDL-cholesterol, which would be expected to increase the risk of CHD. Moreover, it is argued that MUFA have a more beneficial effect on risk factors of CHD than carbohydrate. This effect has been confirmed in studies where carbohydrate has been compared with MUFA under strictly isoenergetic conditions and no weight loss was allowed to occur on the low-fat complexcarbohydrate diet (Luscombe et al. 1999). However, in the studies allowing ad libitum intake the changes in blood lipids are dominated by the slight weight loss induced by the low-fat diet. This finding was illustrated in a study on hyperlipidaemic patients where the dietary fat content was first changed from 35 to $15 \%$ energy under isoenergetic conditions so that body weight was kept constant (Schaefer et al. 1995). Consumption of the low-fat diet under weightmaintenance conditions had lowering effects on plasma total cholesterol, LDL- and HDL-cholesterol levels (-12.5, -17.1 and $-22.8 \%$ respectively). This diet increased plasma triacylglycerol levels $(+47.3 \%)$ and total cholesterol:HDL-cholesterol $(+14.6 \%)$. In contrast, consumption of the low-fat ad libitum diet was accompanied by significant weight loss $(-3.63 \mathrm{~kg} ; P<0.001)$, by a mean decrease in LDL-cholesterol $(-24.3 \%)$, and by mean triacylglycerol levels and total cholesterol: HDL-cholesterol that were not significantly different from values obtained at baseline. This finding has been confirmed in a systematic review and metaanalysis evaluating the effects of the American National Cholesterol Education Program's dietary interventions on major cardiovascular disease risk factors (Yu-Poth et al. 1999).

However, carbohydrate source and GI may be important in relation to the effect on risk factors. Both observational and short-term intervention studies show that a low-GI diet exerts more beneficial effects on LDL- and HDLcholesterol, insulin resistance and plasminogen activator inhibitor-1 activity than a high-GI diet (Frost et al. 1999; Jarvi et al. 1999). However, as mentioned earlier, the only available long-term study, the 6-month CARMEN study, failed to show any adverse effect of a low-fat high-simplecarbohydrate diet on blood lipids (Saris et al. 2000). Thus, the high carbohydrate content of low-fat diets should stem mainly from the complex carbohydrates of different vegetables, fruit and whole grains, which are more satiating for lower energy than fatty foods and are good sources of vitamins, minerals, trace elements and fibre. However, to assist compliance with a low-fat diet it may be necessary to allow for a slightly increased intake of extrinsic sugars.

Recently, a number of randomised intervention trials have shown that a low-fat diet, either alone (Swinburn $e t$ al. 2001) or in combination with physical activity, can reduce the incidence of type 2 diabetes by 50-60\% (Chang, 2001; Tuomulitho et al. 2001). Type 2 diabetes is associated with an almost 10-year reduction in life expectancy, mainly due to increased cardiovascular mortality, and its prevention 
therefore has substantial health benefits. The same diet composition has also been shown to reduce morbidity and mortality in patients with established IHD (Singh et al. 1985; Ornish et al. 1990; de Lorgeril et al. 1999).

\section{Conclusions}

Ad libitum consumption of diets low in fat and high in protein and complex carbohydrates, with a low GI, contributes to the prevention of weight gain in normalweight subjects. It also causes a spontaneous weight loss of $3-4 \mathrm{~kg}$ in overweight subjects, and has beneficial effects on risk factors for diabetes and cardiovascular disease. To prevent obesity and diabetes there are grounds for recommending the combination of increasing the daily physical activity level to a value of at least 1.8 and reducing dietary fat content to $20-25 \%$ energy in sedentary subjects, and to 25-35\% energy in more-physically-active individuals.

Low-fat diets, either as the only intervention, or in combination with exercise, have proven effective in preventing type 2 diabetes in overweight subjects. Since type 2 diabetes is associated with an increased cardiovascular mortality and a reduction of 10 years in longevity, the prevention of this disease will substantially justify the use of low-fat diets for the prevention of cardiovascular disease. A Mediterranean fat-reduced diet may leave room for plenty of fruit, vegetables and fish, and such a diet has been shown to reduce total mortality by $45-60 \%$ in individuals with IHD (Eurodiet Core Report, 2001). The phenomenon that many countries have apparently reduced their average dietary fat content slightly, whilst the population continues to get fatter, has been proclaimed as evidence that it is easier to gain weight on low-fat high-carbohydrate diets than on higher-fat diets. However, the evidence is against this possibility. A meta-analysis of intervention studies comparing ad libitum intakes of higher-fat diets with low-fat diets has clearly shown a reduced energy intake and a reduction in body weight with the low-fat diets. One should also address the well-known phenomenon of underreporting of energy intake, and especially of fat intake, by overweight subjects, which makes the observed fat intake reduction questionable. The obesity epidemic seen in the USA and other countries is predominantly due to an increasingly inactive lifestyle, which reduces the metabolic demand for fat as fuel.

\section{Acknowledgements}

Supported by grants from the Danish Medical Research Council and the Danish Food Technology and Nutrition Program (FØTEK).

\section{References}

Aarsland A, Chinkes D \& Wolfe RR (1997) Hepatic and wholebody fat synthesis in humans during carbohydrate overfeeding. American Journal of Clinical Nutrition 65, 1774-1782.

Agus MSD, Swain JF, Larson CL, Eckert EA \& Ludwig DS (2000) Dietary composition and physiologic adaptions to energy restriction. American Journal of Clinical Nutrition 71, 901-907.

Astrup A (2001a) The role of dietary fat in the prevention and treatment of obesity. Efficacy and safety of low-fat diets.
International Journal of Obesity and Related Metabolic Disorders 25, Suppl. 1, S46-S50.

Astrup A (2001b) Healthy lifestyles in Europe: prevention of obesity and type II diabetes by diet and physical activity. Public Health Nutrition 4, 499-515.

Astrup A, Grunwald GK, Melanson EL, Saris WHM \& Hill JO $(2000 a)$ The role of low-fat diets in body weight control: a metaanalysis of ad libitum intervention studies. International Journal of Obesity and Related Metabolic Disorders 24, 1545-1552.

Astrup A, Hill JO \& Saris WHM (2001) Dietary fat: At the heart of the matter. Science 293, 801-803.

Astrup A \& Raben A (1992) Obesity: An inherited metabolic deficiency in the control of macronutrient balance? European Journal of Clinical Nutrition 46, 611-620.

Astrup A, Ryan L, Grunwald GK, Storgaard M, Saris W, Melanson E \& Hill JO $(2000 b)$ The role of dietary fat in body fatness: evidence from a preliminary meta-analysis of ad libitum low fat dietary intervention studies. British Journal of Nutrition 83, Suppl. 1, S25-S32.

Baer DJ, Rumpler WV, Miles CW \& Fahey GC Jr (1997) Dietary fiber decreases the metabolizable energy content and nutrient digestibility of mixed diets fed to humans. Journal of Nutrition 127, 579-586.

Barboriak JJ \& Meade RC (1970) Effect of alcohol on gastric emptying in man. American Journal of Clinical Nutrition 23, 1151-1153.

Bendixen H, Flint A, Raben A, Høy C-E, Mu H, Xu X, Bartels EM \& Astrup A (2002) Effect of three modified fats and a conventional fat on appetite, energy intake, energy expenditure, and substrate oxidations in healthy men. American Journal of Clinical Nutrition 75, 47-56.

Blundell JE \& Hill AJ (1986) Paradoxical effects of an intense sweetener (aspartame) on appetite. Lancet i, 1092-1093.

Bolton-Smith C \& Woodward M (1994) Dietary composition and fat to sugar ratios in relation to obesity. International Journal of Obesity 18, 820-828.

Bray GA \& Popkin BM (1998) Dietary fat intake does affect obesity. American Journal of Clinical Nutrition 68, 1157-1173.

Campfield LA (1997) Metabolic and hormonal controls of food intake. Highlights of the last 25 years - 1972-1997. Appetite 29, 135-153.

Campfield LA, Smith FJ \& Rosenbaum M (1993) Human hunger: Is there a role for blood glucose dynamics? Appetite 20, 149.

Canty DJ \& Chan MM (1991) Effects of consumption of caloric $v s$. noncaloric sweet drinks on indices of hunger and food consumption in normal adults. American Journal of Clinical Nutrition 53, 1159-1164.

Chang K (2001) Diet and exercise are found to cut diabetes by over half. New York Times 9 August issue. http://www.nytimes.com

Chari ST, Harder H, Teyssen S, Knodel C, Riepl RL \& Singer MV (1996) Effect of beer, yeast-fermented glucose, and ethanol on pancreatic enzyme secretion in healthy human subjects. Digestive Diseases and Sciences 41, 1216-1224.

Colditz GA, Willett WC, Stampfer MJ, London SJ, Segal MR \& Speizer FE (1990) Patterns of weight change and their relation to diet in a cohort of healthy women. American Journal of Clinical Nutrition 51, 1100-1105.

Cordain L, Bryan ED, Melby CL \& Smith MJ (1997) Influence of moderate daily wine consumption on body weight regulation and metabolism in healthy free-living males. Journal of the American College of Nutrition 16, 134-139.

Costill DL (1988) Carbohydrates for exercise: Dietary demands for optimal performance. International Journal of Sports Medicine 9, 1-18.

de Lorgeril M, Salen P, Martin J-L, Monjaud I, Delaye J \& Mamelle $\mathrm{N}$ (1999) Mediterranean diet, traditional risk factors, and the rate of cardiovascular complications after myocardial infarction. 
Final report of the Lyon diet heart study. Circulation 99, 779785 .

Di Meglio DP \& Mattes RD (2000) Liquid versus solid carbohydrate: effects on food intake and body weight. International Journal of Obesity and Related Metabolic Disorders 24, 794-800.

Doucet NA, White MD, Després J-P, Bouchard C \& Tremblay A (1998) Dietary fat composition and human adiposity. European Journal of Clinical Nutrition 52, 2-6.

Dulloo AG, Fathi M, Mensi N \& Girardier L (1996) Twentyfour-hour energy expenditure and urinary catecholamines of humans consuming low-to-moderate amounts of medium-chain triglycerides. A dose-response study in a human respiratory chamber. European Journal of Clinical Nutrition 50, 152-158.

Dulloo AG, Mensi N, Seydoux J \& Girardier L (1995) Differential effects of high-fat diets varying in fatty acid composition on the efficiency of lean and fat tissue deposition during weight recovery after low food intake. Metabolism 44, 273-279.

Eccles M, Freemantle N \& Mason J (1998) North of England evidence based guidelines development project: methods of developing for efficient drug use in primary care. British Medical Journal 316, 1232-1235.

Eurodiet Core Report (2001) Nutrition \& diet for healthy lifestyles in Europe: science \& policy implications. Public Health Nutrition 4, 265-273.

Expert Panel on Detection, Evaluation, and Treatment of High Blood Cholesterol in Adults (2001) Executive summary of the third report of the National Cholesterol Education Program (NCEP) expert panel on detection, evaluation, and treatment of high blood cholesterol in adults (Adult Treatment Panel III). Journal of the American Medical Association 285, 2486-2497.

Flatt PR, Bailey CJ, Kwasowski P, Page T \& Marks V (1984) Plasma immunoreactive gastric inhibitory polypeptide in obese hyperglycemic (ob/ob) mice. Journal of Endocrinology 101, 249-256.

Flint A, Raben A, Blundell JE \& Astrup A (2000) Reproducibility, power and validity of visual analogue scales in assessment of appetite sensations in single meal test studies. International Journal of Obesity and Related Metabolic Disorders 24, 38-48.

Foltin RW, Kelly TH \& Fischman MW (1993) Ethanol as an energy source in humans: Comparison with dextrose-containing beverages. Appetite 20, 95-110.

Frost G, Leeds AA, Doré CJ, Madeiros S, Brading S \& Dornhorst A (1999) Glycaemic index as a determinant of serum HDL-cholesterol concentration. Lancet 353, 1045-1048.

Frost G, Leeds A, Trew G, Margara R \& Dornhorst A (1998) Insulin sensitivity in women at risk of coronary heart disease and the effect of a low glycemic index. Metabolism 47, 1245-1251.

Granfeldt Y, Liljeberg H, Drews A, Newman R \& Björck I (1994) Glucose and insulin responses to barley products: influence of food structure and amylose-amylopectin ratio. American Journal of Clinical Nutrition 59, 1075-1082.

Haulrik N, Toubro S, Dyerberg J, Stender S, Skou AR \& Astrup A (2002) The effect of protein and methionine intake on plasma homocysteine concentrations: a 6 month randomized controlled trial in overweight subjects. American Journal of Clinical Nutrition (In the Press).

Hellerstedt WL, Jeffery RW \& Murray DM (1990) The association between alcohol intake and adiposity in the general population. American Journal of Epidemiology 132, 594-611.

Hill JO, Peters JC, Lin D, Yakubu F, Greene H \& Swift L (1993) Lipid accumulation and body fat distribution is influenced by type of dietary fat fed to rats. International Journal of Obesity 17 , 223-236.

Holt S, Brand-Miller J, Soveny C \& Hansky J (1992) Relationship of satiety to postprandial glycemic, insulin and cholecystokinin responses. Appetite 18, 129-141.
Hoppe C, Mølgaard C, Juul A \& Michaelsen KF (2001) Protein intake in infancy is related to body size but not to adiposity in 10-y old children. International Journal of Obesity and Related Metabolic Disorders 25, Suppl. 2, S64.

Järvi AE, Karlstrom BE, Granfeldt YE, Björck IE, Asp NG \& Vessby Bo (1999) Improved glycemic control and lipid profile and normalized fibrinolytic activity on a low-glycemic index diet in type 2 diabetic patients. Diabetes Care 22, 10-18.

Jones KL, Doran SM, Hveem K, Barholomeusz FDL, Morley JE, Sun WM, Chatterton BE \& Horowitz M (1997) Relation between postprandial satiation and antral area in normal subjects. American Journal of Clinical Nutrition 66, 127-132.

Jones PJH, Pencharz PB \& Clandinin MT (1985) Whole body oxidation of dietary fatty acids: implications for energy utilization. American Journal of Clinical Nutrition 42, 769-777.

Jones PJH, Ridgen JE, Phang PT \& Birmingham CL (1992) Influence of dietary fat polyunsaturated to saturated ratio on energy substrate utilization in obesity. Metabolism 41, 396-401.

Jones PJH \& Schoeller DA (1988) Polyunsaturated:saturated ratio of diet fat influences energy substrate utilization in the human. Metabolism 37, 145-151.

Katan MB, Grundy SM \& Willett WC (1997) Beyond low-fat diets. New England Journal of Medicine 337, 563-566.

Lawton CL, Delargy HJ, Brockman J, Smith FC \& Blundell JE (2000) The degree of saturation of fatty acids influences post-ingestive satiety. British Journal of Nutrition 83, 473-482.

Leibowitz SF (1988) Hypothalamic paraventricular nucleus: Interaction between alpha 2-noradrenergic system and circulating hormones and nutrients in relation to energy balance. Neuroscience Biobehavioural Reviews 12, 101-109.

Lissner L, Levitsky DA, Strupp BJ, Kalkwarf HJ \& Roe DA (1987) Dietary fat and the regulation of energy intake in human subjects. American Journal of Clinical Nutrition 46, 886-892.

Ludwig DS, Peterson KE \& Gortmaker SL (2001) Relation between consumption of sugar-sweetened drinks and childhood obesity: a prospective, observational analysis. Lancet 357, 505-508.

Luscombe ND, Noakes M \& Clifton PM (1999) Diets high and low in glycemic index versus high monounsaturated fat diets: effects on glucose and lipid metabolism in NIDDM. European Journal of Clinical Nutrition 53, 473-478.

Marckmann P \& Astrup A (2000) Fatty diets are unhealthy - even those based on monounsaturates. American Journal of Clinical Nutrition 72, 853-854.

Matsuo T, Shimomura Y, Saitoh S, Tokuyama K, Takeuchi H \& Suzuki M (1995) Sympathetic activity is lower in rats fed a beef tallow diet than in rats fed a safflower oil diet. Metabolism 44, 934-939.

Mattes RD (1996) Dietary compensation by humans for supplemental energy provided as ethanol or carbohydrate in fluids. Physiology and Behavior 59, 179-187.

Mayer J (1953) Glucostatic mechanism of regulation of food intake. New England Journal of Medicine 249, 13-16.

Miles C (1992) The metabolizable energy of diets differing in dietary fat and fiber measured in humans. Journal of Nutrition 122, 306-311.

Murgatroyd PR, Van de Ven MLHM, Goldberg GR \& Prentice AM (1996) Alcohol and the regulation of energy balance: overnight effects on diet-induced thermogenesis and fuel storage. British Journal of Nutrition 75, 33-45.

National Institutes of Health (2000) The Practical Guide: Identification, Evaluation, and Treatment of Overweight and Obesity in Adults. NIH Publication no. 00-4084. Bethesda, MD: NIH.

Ornish D, Brown SE, Scherwitz LW, Billings JH, Armstrong WT, Ports TA, McLanahan SM, Kirkeeide RL, Brand RJ \& Gould KL (1990) Can lifestyle changes reverse coronary heart disease? Lancet 336, 129-133. 
Pirola RC \& Lieber CS (1972) The energy cost of the metabolism of drugs including ethanol. Pharmacology 7, 185-196.

Poppitt SD, Eckhardt JW, McGonagle J, Murgatroyd PR \& Prentice AM (1996) Short-term effects of alcohol consumption on appetite and energy intake. Physiology and Behavior 60, $1063-1070$.

Porikos KP, Hesser MF \& van Itallie TB (1982) Caloric regulation in normal-weight men maintained on a palatable diet of conventional foods. Physiology and Behavior 29, 293-300.

Raben A, Holst JJ, Christensen NJ \& Astrup A (1996) Determinants of postprandial appetite sensations: Macronutrient intake and glucose metabolism. International Journal of Obesity and Related Metabolic Disorders 20, 161-169.

Raben A, Jensen ND, Marckmann P, Sandström B \& Astrup A (1995) Spontaneous weight loss during 11 weeks' ad libitum intake of a low-fat/high-fiber diet in young, normal-weight subjects. International Journal of Obesity and Related Metabolic Disorders 19, 916-923.

Raben A, Møller AC, Vasilaras TH \& Astrup A (2002) Sucrose vs. artifical sweeteners: different effects on ad libitum food intake and body weight after 10 weeks in overweight subjects. American Journal of Clinical Nutrition (In the Press).

Reid M \& Hammersley R (1998) The effect of blind substitution of aspartame-sweetened for sugar-sweetened soft drinks on appetite and mood. British Food Journal 100, 254-259.

Rogers PJ \& Blundell JE (1989) Separating the actions of sweetness and calories: effects of saccharin and carbohydrates on hunger and food intake in human subjects. Physiology and Behavior 45, 1093-1099.

Russek M (1970) Demonstration of the influence of a hepatic glucosensitive mechanism on food-intake. Physiology and Behavior 5, 1207-1209.

Saris WHM, Astrup A, Prentice AM, Zunft HJH, Formiguera X, Verboeket-van de Venne WPHG, Raben A, Poppitt SD, Seppelt B, Johnston S, Vasilaras TH \& Keogh GF (2000) Randomized controlled trial of changes in dietary carbohydrate/fat ratio and simple vs. complex carbohydrates on body weight and blood lipids: the CARMEN study. International Journal of Obesity and Related Metabolic Disorders 24, 1310-1318.

Scalfi L, Coltorti A \& Contalde F (1991) Postprandial thermogenesis in lean and obese subjects after meals supplemented with medium-chain and long-chain triglycerides. American Journal of Clinical Nutrition 53, 1130-1133.

Schaefer EJ, Lichtenstein AH, Lamon-Fava S, McNamara JR, Schaefer MM, Rasmussen H \& Ordovas JM (1995) Body weight and low-density lipoprotein cholesterol changes after consumption of a low-fat ad libitum diet. Journal of the American Medical Association 274, 1450-1455.

Schick RR, Zimmermann J, Van Walde T, Schusdziarra V \& Classen M (1992) Glucagon-like peptide (GLP)-1 7-36-amide: A central suppressor of food intake in rats. Gastroenterologia 102, A756.

Schwartz MW (2000) Biomedicine. Staying slim with insulin in mind. Science 289, 2122-2125.

Sepple CP \& Read NW (1989) Gastrointestinal correlates of the development of hunger in man. Appetite 13, 183-191.

Shimizu N, Oomura Y, Novin D, Grijalva CV \& Cooper PH (1983) Functional correlations between lateral hypothalamic glucosesensitive neurons and hepatic portal glucose-sensitive units in the rat. Brain Research 265, 49-54.

Shimomura Y, Tamura T \& Suzuki M (1990) Less body fat accumulation in rats fed a safflower oil diet than in rats fed a beef tallow diet. Journal of Nutrition 120, 1291-1296.

Singh RB, Rastogi SS, Verma R, Laxmi B, Singh R \& Ghosh S (1992) Randomised controlled trial of cardioprotective diet in patients with recent acute myocardial infarction: result of one-year follow up. British Medical Journal 304, 1015-1019.

Skov AR, Toubro S, Bülow J, Krabbe K, Parving HH \& Astrup A (1999a) Changes in renal function during weight loss induced by high vs. low-protein low-fat diets in overweight subjects. International Journal of Obesity and Related Metabolic Disorders 23, 1170-1177.

Skov AR, Toubro S, Rønn B, Holm L \& Astrup A (1999b) Randomized trial on protein versus carbohydrate in ad libitum fat reduced diet for the treatment of obesity. International Journal of Obesity and Related Metabolic Disorders 23, 528-536.

Slabber M, Barnard HC, Kuyl KJM, Dannhauser A \& Schall R (1994) Effects of a low-insulin-response, energy-restricted diet on weight loss and plasma insulin concentrations in hyperinsulinemic obese females. American Journal of Clinical Nutrition 60, 48-53.

Smith GP \& Gibbs J (1987) The effect of gut peptides on hunger, satiety, and food intake in humans. Annals of the New York Academy of Sciences 499, 132-136.

Spieth LE, Harnish JD, Lenders CM, Raezer LB, Pereira MA, Hangen SJ \& Ludwig DS (2000) A low-glycemic index diet in the treatment of pediatric obesity. Archives of Pediatrics and Adolescent Medicine 154, 947-951.

Stellman SD \& Garfinkel L (1986) Artificial sweetener use and one-year weight change among women. Preventive Medicine 15 , 195-202.

Stubbs RJ \& Habron CG (1996) Covert manipulation of the ratio of medium- to long-chain triglycerides in isoenergetically dense diets: effect on food intake in ad libitum feeding men. International Journal of Obesity and Related Metabolic Disorders 20, 435-444.

Suter PM, Schutz Y \& Jequier E (1992) The effect of ethanol on fat storage in healthy subjects. New England Journal of Medicine 326, 983-987.

Swinburn BA, Metcalf PA \& Ley SJ (2001) Long-term (5-year) effects of a reduced-fat diet intervention in individuals with glucose intolerance. Diabetes Care 24, 619-624.

Taubes G (2001) The soft science of dietary fat. Science 291, 2536-2545.

Tordoff MG \& Alleva AM (1990a) Oral stimulation with aspartame increases hunger. Physiology and Behavior 47, 555-559.

Tordoff MG \& Alleva M (1990b) Effect of drinking soda sweetened with aspartame or high-fructose corn syrup on food intake and body weight. American Journal of Clinical Nutrition 51, 963-969.

Tremblay A, Lavallée N, Almeras N, Allard L, Després J-P \& Bouchard C (1991) Nutritional determinants of the increase in energy intake associated with a high-fat diet. American Journal of Clinical Nutrition 53, 1134-1137.

Tuomiletho J, Lindström J, Eriksson JG, Valle TT, Hämäläinen H, Ilanne-Parikka $\mathrm{P}$, Keinänen-Kiukannniemi $\mathrm{S}$, Laakso $\mathbf{M}$, Louheranta A, Rastas M, Salminen V \& Uusitupa M (2001) Prevention of type 2 diabetes mellitus by changes in lifestyle among subjects with impaired glucose tolerance. New England Journal of Medicine 344, 1343-1350.

van Marken Lichtenbelt WD, Mensink RP \& Westerterp KR (1997) The effect of fat composition of the diet on energy metabolism. Zeitschrift fur Ernährungswissenschaft 36, 303-305.

Van Wymelke V, Himaya A, Louis-Sylvestre J \& Fantino M (1998) Influence of medium-chain and long-chain triacylglycerols on the control of food intake in men. American Journal of Clinical Nutrition 68, 226-234.

Verdich C, Toubro S, Buemann B, Lysgard Madsen J, Juul Holst J \& Astrup A (2001) The role of postprandial releases of insulin and incretin hormones in meal-induced satiety-effect of obesity 
and weight reduction. International Journal of Obesity and Related Metabolic Disorders 25, 1206-1214.

Westerterp-Plantenga MS \& Verwegen CRT (1999) The appetizing effect of an apéritif in overweight and normal-weight humans. American Joumal of Clinical Nutrition 69, 205-212.

Willett WC (1998) Is dietary fat a major determinant of body fat? American Journal of Clinical Nutrition 67, 556S-562S.
Wolever TMS Jenkins DJA, Vuksan V, Jenkins AL, Wong GS \& Josse RG (1992) Beneficial effect of low-glycemic index diet in overweight NIDDM subjects. Diabetes Care 15, 562-564.

Yu-Poth S, Zhao G, Etherton T, Naglak M, Jonnalagadda S \& Kris-Etherton PM (1999) Effects of the National Cholesterol Education Programs step I and step II dietary intervention programs on cardiovascular disease risk factors: A metaanalysis. American Journal of Clinical Nutrition 69, 632-646. 